\title{
Estimation of Heterosis for Some Traits in Linseed (Linum Usitatissimum L.)
}

\author{
M.P.Reddy ${ }^{1}$, B.T.Arsul ${ }^{2}$, N.R.Shaik ${ }^{3}$ and J.J.Maheshwari ${ }^{4}$ \\ ${ }_{1,2}$ and 3 PG Student, Botany Section, College of Agriculture, Nagpur (M.S.) \\ ${ }^{4}$ Associate Professor, Botany Section, College of Agriculture, Nagpur (M.S.) \\ All India Co-ordinated Research Project on Linseed, Dr. PanjabraoDeshmukhKrishiVidyapeeth, College of \\ Agriculture, Nagpur-440001, Maharashtra, India.
}

\begin{abstract}
For the estimation of mid-parent and better-parent heterosis in Linumusitatissimum L. genotypes an experiment was conducted at Department of Agricultural Botany, College of Agriculture, Nagpur during 200910 and 2010-11 using line $x$ tester analysis. All the $60 \mathrm{Fl}$ hybrids and their parents (20 males +3 females) were planted in a randomized complete block design with two replications. Out of 60 hybrids, significant negative mid-parent and better-parent heterosis were estimated in 9 and 21 hybrids for plant height, in 20 and 35 hybrids for days to 50\% flowering, in 18 and 30 crosses for days to physiological maturity and in 10 and 22 crosses for budfly (Dasyneuralini) infestation, in 17 and 32 crosses for alternaria blight (Alternarialini) respectively. Positive significant heterosiswere estimated in 51 and 41 crosses for number of branches plant ${ }^{-1}$. However, significant positive mid -parent and better-parent heterosis were recorded in 57 and 55 hybrids for no of capsule plant ${ }^{-1}$, in 39 and 20 hybrids for 1000 seed weight, in 45 and 34 hybrids for yield plant ${ }^{-1}$ respectively. Among parents, Karthika, ACC NO 4/47, PKVNL-260, EC-9825 and GS-234 proved to be superior when used as parents in most of the hybrid combinations. Maximum positive significant heterosis over better-parent were observed in crosses Padmini $x$ ACCNO4/47, Karthika x JRF-5, Padmini x LCK-8605, PKVNL-260 $x$ ACCNO4/47, PKVNL-260 $x$ Eita and Karthika $x$ EC-9825 for early flowering and plant height, branches plant ${ }^{1}$, days to physiological maturity, yield plant ${ }^{-1}$, number of capsules plant ${ }^{-1}$ and 1000 seed weight respectively. From present experiment crosses PKVNL-260 x ES-44 and PKVL-260 x EC-9825 were found best for budfly infestation and alternaria infestation respectively.
\end{abstract}

Keywords: heterosis; mid-parent; better-parent; Linumusitatissimum; Line x Tester analysis

\section{Introduction}

Linseed (Linumusitatissimum L.) belongs to the genus Linum of the family Linaceae. The somatic chromosome number of the cultivated species is $2 n=30$. is cultivated for the main products fibre (flax fibre) and seed oil (linseed) or both (dual purpose linseed), but recently it has gained a new interest in the emerging market of functional food due to its high content of fatty acids, alpha linolenic acid (ALA), an essential Omega3 fatty acid and lignin oligomers which constitute about $57 \%$ of total fatty acids in linseed. Traditionally, the oil pressed from the seed (linseed oil) has been used for a variety of industrial purposes and the oil free meal could be fed to livestock. Omega-3 fatty acids lower levels of triglycerides in the blood, thereby reducing heart disease, and also show promise in the battle against inflammatory diseases such as rheumatoid arthritis. Linolenic acid (LA), an Omega-6 essential fatty acid is also found in linseed. Linseed oil contains three times as much Omega-3 fatty acid fatty than Omega-6 fatty acid. Linseed crop suffers from several diseases and insect pest in India. The significant yield losses occurs in linseed due to budfly (Dasyneuralini) (20 to 97\%), alternaria blight (Alternarialini) \& powdery mildew (Odium lini) (up to $60 \%$ ) Srivastavaet al.,(1997). Therefore, there is a need to develop varieties resistant to pests and diseases to stabilize the yield potentials of linseed varieties. Therefore, this research work helps in developing varieties resistant to pest and diseases to stabilize the yield potentials of linseed varieties. The commercial exploitation of heterosis led to the remarkable yield advances in several cross pollinated crops. In self pollinated crops, it is now well recognized that heterosis is very useful increasing productivity. The magnitude of heterosis provides a basis for genetic diversity and guideline to the choice of desirable parents for developing superior $F_{1}$ hybrids so as to exploit hybrid vigour and for building gene pool to be exploitation in population improvement.

The successes of hybrid breeding are the reason for its expansion in all most all major fields of agricultural plants and animals. Its role in vegetable and major field crops is undeniable. For developing a hybrid, as a first step information available on genetic analysis of important characters is collected. This information are then used to combine desirable traits in a single hybrid. For this purpose, genetic information on heterosis is useful for developing breeding strategies to meet the demands of increased population. It has become a common practice of the plant breeder working with crop plants to obtain genetic information from line $\mathrm{x}$ tester cross progenies. It is necessary to have detailed information about the desirable parental combination in 
any breeding program which can reflect a high degree of heterotic response. Therefore, heterotic studies can provide the basis for the exploitation of valuable hybrid combinations in future breeding programs.

In the present studies heterosis (mid-parent and better-parent) was estimated for seed yield and some important agronomic traits in F1 generation of linseed genotypes using line $\mathrm{x}$ tester model suggested by Kempthorne (1957).

\section{Materials And Methods}

The experimental material included in present study comprised of $60 \mathrm{~F}_{1}$ 's and 23 parents $(20$ males +3 females) were grown in single progeny rows in a randomized block design with two replications. The plant to plant distance was $30 \mathrm{~cm}$ with 24 plants in each progeny row. Data were recorded on five randomly selected plants of each family for nine characters viz, days to $50 \%$ flowering, plant height $(\mathrm{cm})$,number of capsules per plant, number of branches per plant, days to maturity, seed yield per plant,1000 seed weight(g), budfly infestation (\%) and alternaria blight infestation (\%). The data was subjected to analysis of variance according to Panse and Sukhatme (1954) the percent increase (+) or decrease (-) of $F_{1}$ cross over mid parent as well as better parent was calculated to observe heterotic effects of all the parameters. To estimation of heterosis over the midparent and better-parent was calculated using the procedure of Shull, 1908 and (Fonseca and Patterson, 1968) respectively. The difference of $F_{1}$ mean from the respective mid-parent and better-parent values was evaluated by using t-test according to Wynne et al., (1970).

\section{Results And Discussion}

Analysis of variance revealed highly significant (at $\mathrm{P} \leq 0.01$ ) differences among the parents and their $\mathrm{F}_{1}$ hybrids for all characters (Table I). All the 60 hybrids were compared with mid-parent heterosis and betterparent heterosis, respectively.

Small and medium plant stature in linseed crop is preferred because it can tolerate heavy winds and can be prevented from lodging; therefore, negative heterosis is useful regarding plant height. It is clear from the (Table II) that mid-parent heterosis ranged from -30.67 to 21.95 percent in the crosses Padmini $x$ Acc no4/47 and Karthika x EC-4168 respectively. Crosses Padmini x ACC NO4/47 and Padmini x EC-9825 showed significant decrease in palnt height over mid-parent. Nine crosses showed significant negative heterosis and seven crosses showed significant positive heterosis for plant height. Better-parent heterosis ranged from -32.40 (Padmini x ACCNO4/47) to 15.26 percent (Karthika x EC-4168). Twenty one crosses showed negative significant heterosis over better-parent heterosis. Similarly early flowering in linseed can provide adequate time for grain formation process and can certainly cause early maturity higher yields; therefore, negative heterosis is desirable for flowering. The data presented in Table II for 50\% flowering showed that out of 60 crosses, Karthika x A-95-B (-26.49) exhibited significant earliness for this character followed by Karthika $\mathrm{x}$ ACCNO4/47 showed significant heterosis over mid-parent. None of the crosses showed positive significant mid-parent and better-parent heterosis. Twenty crosses showed significant negative heterosis over mid-parent and 35 crosses exhibited negative better-parent heterosis.

In linseed, short stature with vigorous structure containing more number of branches provide opportunity for more yields, so positive heterosis is desirable for number of primary branches. Heterosis estimates over midparent (Table III) showed that out of 60 crosses, 51 crosses had positive effects where values ranged from 15.35 (Karthika x JRF-5) to $139.26 \%$ (Padmini x GS-234). Fifty one crosses showed positive significant heterosis over mid-parent while one cross negative heterosis over mid-parent. Maximum mid-parent heterosis found in crosses padmini x GS-234 followed by Padmini x EC-9825, PKVNL-260 x EC-9825 and Padmini x EC-4168. Better-parent heterosis ranged from -27.66 to 137.80 percent in crosses Karthika X JRF-5 and Padmini x GS-234 respectively. Out of 60 crosses 41 showed positive better-parent heterosis. Maximum heterosis over better-parent was observed in Padmini x GS-234. Early maturity is useful in most of the plant species especially linseed where delayed maturity causes losses to yield and quality of oil due to rise in temperature; therefore, negative heterosis is desirable for early maturity. Heterotic data presented in Table-III showed that out of 60 crosses, 18 crosses showed significant negative heterosis over mid - parent and the data for these crosses ranged from -7.39 to -15.60. The cross Padmini x LCK-8605 showed negative significant heterosis over -15.60 (midparent) and -21.3 (better-parent).

In the present study mid-parent heterosis for seed yield plant ${ }^{-1}$ ranged from 50.86 to 217.86 percent in crosses (Table IV) Karthika x Ayogi and Padmini x JRF-5 respectively. Forty five crosses exhibited positive significant mid-parent heterosis and thirty four crosses showed positive better-parent heterosis. None of the crosses showed negative significant heterosis over mid-parent and better-parent. Maximum heterosis over midparent for yield plant ${ }^{-1}$ found in Padmini x JRF-5. Better-parent ranged from 53.42 to 178.44 percent in crosses PKVNL-260 x ACCNO4/47 and Karthika x Eita. Highest positive significant heterosis for number of capsules ${ }^{-1}$ over better-parent was observed in crosses PKVNL-260 x Eita (260.36) followed by Padmini x GS-234(253.43) and Karthika x Eita (240.24). The maximum heterosis for number of capsules ${ }^{-1}$ over better-parent (Table II) was 
showed by PKVNL-260 x EC-9825 (224.42) followed by PKVNL-260 x Eita (200.75) and Padmini x EC-4168 (200.00).For 1000 Seed weight thirty nine crosses exhibited significant positive heterosis for 1000 Seed weight over mid-parent. Maximum positive heterosis over mid-parent was shown by PKVNL-260 x EC-1424 (45.20) followed by Karthika x EC-9825 (40.43) and PKVNL-260 x A-95-B (37.70). Twenty crosses showed positive heterosis over better-parent (Table II). Maximum positive heterosis for 1000 Seed weight over better-parent was recorded by cross Karthika x GS-15 (33.24) followed by Karthika x Ec-9825 (31.36) and PKVNL-260 x A-125 (28.66). The results of this study are similar to earlier findings of Sakhare (1990) reported significant positive heterosis for number of branches plant ${ }^{-1}$ in linumgenotypes.

Linseed crop suffers from several diseases and insect pest in india. The heterosis for budfly infestation ranged from -50.83 to 74.10 percent in crosses (Table IV) Padmini x Ayogi and PKVNL-260 x BR-1 respectively. The cross Padmini x Ayogi exhibited significant negative heterosis over mid-parent (Table IV). The further revealed that maximum negative heterosis over better-parent was recorded by cross PKVNL-260 x ES-44.The significant yield loss occurs in linseed due to alternaria blight therefore, negative heterosis is desirable for pest and diseases. The cross Padmini x EC-1424 exhibited significant negative heterosis (-50.58) over mid-parent. The further revealed that maximum negative heterosis $(-62.58)$ over better-parent (Table IV) was recorded by cross PKVNL-260 x EC-9825. Early flowering and maturity in linseed genotypes is preferred over late flowering/ maturing genotypes because earliness of these traits might certainly help to get early maturing lines that could not only tolerate or escape heat stress but could also provide sufficient time for the cultivation of next crop. Shorterplants with greater numbers of branches are considered desirable because these traits help plants to tolerant winds. Keeping in view the importance of early flowering and maturity and shorter plant height, emphasis was focused on negative heterosis for these characteristics. In the present experiment, negative heterotic values for these traits was noted for the cross Padmini x ACCNO4/47. Padmini x LCK-8605 cross showing significant negative heterosis over better-parent suggested that these crosses could be used to develop new early maturing lines. Earlier findings of Mishra and Rai (1993) verified the results of this study. They reported significant negative mid-parent and better-parent heterosis for plant height, flowering and maturity in linumusitatissimum. The findings of similar nature were obtained by Sheikh, I.A and J. N. Singh (2001); Anandet al., (1972); Badwal and Guptha (1974), Galkin (1973 b), Singh et al.,(1975) and Wang et al., (1997). Since number of branches plant ${ }^{-1}$ is one of the major yields contributing traits hence more branches plant $^{-1}$ are desirable, therefore positive values are preferred. The presence of significantly positive heterosis for branches plant ${ }^{-1}$ in crosses indicates the potential of their use for developing high yielding genotypes. The presence of high levels of mid and better-parent heterosis indicates a considerable potential to embark on breeding of hybrid cultivars in linumusitatissimum. The results of this study are similar to earlier findings of Rao and Singh (1983), Wang etal., (1997), Patil and Chopde (1983), Dakhore et al. (1987 a) and Naushad Ali Turi1 et al., (2006) reported significant positive heterosis for number of branches plant ${ }^{-1}$ in linum genotypes. The maximum heterosis for number of capsules ${ }^{-1}$ and seed yield plant ${ }^{-1}$ over better-parent was showed by PKVNL-260 x EC-9825 and Karthika x Eita crosses respectively. Similar results were also reported by Singh et al. (1983), Mishra and Rai (1993), Sakhare (1990), Saraswat and Satyandrakumar (1993) and Patil and Chopde (1983).

\section{Acknowledgement}

The author is grateful to Dr. P. B. Ghorpade for providing seed materials from AICRP on Linseed and Prof J.J. Maheshwari, Dr. (Mrs.) S. R. Patil, Dr Y Suresh Reddy, Mula Mohan Reddy, Shri MCV Rami Reddy, M.Sunki Reddy and M.Siva Reddy for their help and valuable suggestions during the work.

\section{References}

[1]. Anand, I.J., B.S. Rana and O.P. Jain, 1972.Estimation of genetic variances by full sib and half sib analysis in linseed.SABRO Nesletter. 4: 33-37

[2]. Badwal, S.S., V.P. Gupta and Harbans Singh, 1974. Genetic analysis of seed yield and it's component in linseed, Indian J. Agric. Sci. 44(7):473-7

[3]. Chandra, S., 1978. The analysis of heterosis and combining ability for some quantitative character in Linumusitatissimum L.,GeneticaSlecnteni. 14:17-25

[4]. Dakhore, S.R., M.N. Narkhede and P.W. Khorgade,1987a. Heterosis in relation to combining ability effects in linseed (Linumusitatissimum L.)., PKV. Res. J. 11:7-12

[5]. Fonseca, S. and F.L. Patterson, 1968. Hybrid vigour in a seven parent diallel cross in common wheat (T. aestivum), Crop Sci. 85-88

[6]. Galkin, F.M. 1973 b. Heterosis in intervarietal hybrid of linseed, ReferatinylZhurnal. 2:7-10

[7]. Kansal, K.K. and S.C. Gupta, 1981. Note on Heterosis in linseed,J. agric. Sci. 51:680-2

[8]. Kempthorne, O., 1957. An introduction to genetic statistics, John Wiley and Sons,Inc., New York

[9]. Mishra, V.K., M. Rai, 1993. The Indian Journal of Genetics and Plant Breeding Volume 53: 161-164

[10]. Naushad Ali Turil et al., 2006; Journal of Agricultural and Biological Science.1: 6-10

[11]. Panse, V.G.and P.V. Sukhatme, 1967. Statistical method for agriculture research workers II edition, ICAR New Delhi.

[12]. Patil, V. D., and P. R. Chopade, 1983. Heterosis in relation to general and specific combining ability effects in linseed,Indian J. Genet.,43: 226-8

[13]. Rao, S.R., and S.P. Singh, 1983: Heterosis and inbreeding depression in linseed,Indian J. Sci. 53: 409-17 
[14]. Sakhare, B.A. 1990. Line x tester analysis in linseed (Linumusitatissimum L.). Unpublished M.sc. (Agri.) Thesis submitted to PKV, Akola.

[15]. Saraswat, A.V. and Satendrakumar, 1993.Heterosis and inbreeding in some early hybrids of linseed. Heterosis breeding in crop plants, Theory and application: Short communication: symposium. Ludhiana.3: 22-24

[16]. Sheikh, I.A., and J.N. Singh. 2001. Heterosis in Indian mustard hybrids derived using male sterile lines for yield and component characters, Crop Research Hisar. 21: 98-203

[17]. Shull, G.H. 1908: The composition of field of maize, Rept. Am. Breeders Assoc. 4: 246-301

[18]. Srivastava, R.L.; Jyothisingh, karan Husain, Y.P. Malik, S.D. Dubey, J. Rai and MadhuBajpai, 1997. Linseed.:In:Efficient management of Dryland crops in india-oilseeds (Edited by R.P.Singh, P.S.Reddy, V.Kiresur) PP. 228-256

[19]. Wang, Yu, Fu, Yan and ZangFeng, 1997. Study on heterosis and affinity of flax, China'sfibre crops 2: 10-13

[20]. Wynne, J.C., D.A. Emery and P.M. Rice, 1970. Combining ability analysis over environments in spring wheat,.Wheat Infor.Serv. Japan. 67:21-24

Table I. Mean squares for days to 50\% flowering, plant height, capsules-1, branches plant-1, days to maturity, 1000 seed weight, yield per plant, budfly (\%) and alternaria (\%) in Linumusitatissimum L. genotypes.

\begin{tabular}{|c|c|c|c|c|c|c|c|c|c|c|}
\hline & & \multicolumn{9}{|c|}{ Characters } \\
\hline S.O.V. & D.F. & $\begin{array}{l}\text { Days to } \\
50 \% \\
\text { flowering }\end{array}$ & $\begin{array}{l}\text { Plant } \\
\text { height( }(\mathrm{Cm})\end{array}$ & $\begin{array}{l}\text { Capsules } \\
\text { plant"-1 }\end{array}$ & $\begin{array}{l}\text { Branches } \\
\text { plant! }\end{array}$ & $\begin{array}{l}\text { Days to } \\
\text { maturity }\end{array}$ & $\begin{array}{l}1000 \text { seed } \\
\text { weight(gm) }\end{array}$ & $\begin{array}{l}\text { Yield } \\
\text { plant:(gm) }\end{array}$ & Budfly $(\%)$ & $\begin{array}{l}\text { Alternaria } \\
(\%)\end{array}$ \\
\hline Replications & 1.00 & 27.08 & 48.86 & 224.49 & 0.36 & 7.50 & 0.15 & 0.04 & 0.92 & 7.87 \\
\hline Genotypes & 59.00 & $6.06^{* 2}$ & $57.43^{* *}$ & $1170.05^{* *}$ & $3.18^{* *}$ & $27.15^{* *}$ & $1.52^{* *}$ & $2.60^{* *}$ & $214.24^{* *}$ & $19.39^{* *}$ \\
\hline Error & 59.00 & 8.06 & 6.17 & 57.21 & 0.24 & 16.60 & 0.09 & 0.34 & 18.58 & 2.37 \\
\hline
\end{tabular}

* Significant at $5 \%$ and ** Significant at $1 \%$ 
Estimation of Heterosis for Some Traits in Linseed (Linum Usitatissimum L.)

Table II: Heterotic effects for Days to $50 \%$ flowering, Plant Height $(\mathrm{Cm})$ and Capsules plant ${ }^{-1}$

\begin{tabular}{|c|c|c|c|c|c|c|}
\hline & \multicolumn{2}{|c|}{ Branches plant $^{-1}$} & \multicolumn{2}{|c|}{ Days to maturity } & \multicolumn{2}{|c|}{1000 seed weight } \\
\hline & \multicolumn{2}{|c|}{ Days to $50 \%$ flowering } & \multicolumn{2}{|c|}{ Plant Height $(\mathrm{Cm})$} & \multicolumn{2}{|c|}{ Capsules plant $^{-1}$} \\
\hline Crosses & $\mathrm{MP}$ & $\mathrm{BP}$ & MP & $\mathrm{BP}$ & MP & $\mathrm{BP}$ \\
\hline Karthika x A-95-B & $-26.49 * *$ & $-12.32 * *$ & -9.05 & $-14.93 * *$ & $121.0^{* *}$ & $85.86 * *$ \\
\hline Karthika x EC-1424 & $-11.79 * *$ & $-15.94 * *$ & $14.23^{*}$ & -5.60 & $164.16^{* *}$ & $130.17^{* *}$ \\
\hline Karthika x GS-234 & $-9.92 *$ & $-14.49 * *$ & $15.78^{* *}$ & $14.07 *$ & $63.78^{* *}$ & $31.65^{*}$ \\
\hline Karthika x A-125 & $-9.58^{*}$ & $-14.49 * *$ & 1.89 & 0.32 & $35.10^{*}$ & 23.63 \\
\hline Karthika x Eita & $-11.45^{* *}$ & $-15.94 * *$ & -9.97 & $-12.14 *$ & $240.24 * *$ & $166.67^{* *}$ \\
\hline Karthika x GS-15 & $-13.24^{* *}$ & $-14.49 * *$ & 9.21 & 8.13 & 19.77 & 1.69 \\
\hline Karthika x EC-1392 & -4.25 & $-10.14^{*}$ & -3.32 & -7.18 & $101.63 * *$ & $56.12^{* *}$ \\
\hline Karthika x PKDL-18 & $-13.55^{* *}$ & $-14.49 * *$ & 0.09 & $-12.00 * *$ & $83.98^{* *}$ & $55.06^{* *}$ \\
\hline KarthikaxAyogi & -7.69 & $-13.04 * *$ & -4.62 & -10.33 & $73.29 * *$ & $54.64^{* *}$ \\
\hline Karthika x ES-44 & $-9.96 * *$ & $-11.59 * *$ & -6.28 & -9.09 & $72.73^{* *}$ & $62.96 * *$ \\
\hline Karthika x EC-4168 & -7.58 & $-11.59 * *$ & $21.95^{* *}$ & $15.26^{* *}$ & $215.59 * *$ & $183.97^{* *}$ \\
\hline Karthika x EC-9825 & $-9.02^{*}$ & $-15.94 * *$ & -2.54 & -4.24 & $105.20^{* *}$ & $93.67^{* *}$ \\
\hline Karthika x EC-544 & $-9.45^{*}$ & $-16.67^{* *}$ & 9.54 & 8.46 & $95.24^{* *}$ & $65.82^{* *}$ \\
\hline Karthika x KL-178 & $-9.49 *$ & $-10.14^{*}$ & 0.20 & -2.64 & $71.55^{* *}$ & $52.00 * *$ \\
\hline Karthika x JRF-5 & $-11.83^{* *}$ & $-12.77^{* *}$ & 0.81 & -6.32 & $142.92 * *$ & $124.47^{* *}$ \\
\hline Karthika x LCK-8605 & $-11.03^{* *}$ & $-15.22 * *$ & 5.98 & 5.16 & $69.62 * *$ & $35.70 * *$ \\
\hline Karthika x BR-1 & $-10.69 * *$ & $-15.22 * *$ & -1.75 & -7.58 & $165.56^{* *}$ & $101.69 * *$ \\
\hline Karthika x ACCNO4/47 & $-14.80 * *$ & $-15.11^{* *}$ & 3.18 & -1.87 & $129.98^{* *}$ & $128.54^{* *}$ \\
\hline Karthika x LCK-88062 & $-11.03^{* *}$ & $-12.32 * *$ & 0.99 & -4.40 & $160.69^{* *}$ & $99.37 * *$ \\
\hline KarthikaxNeelum & $-9.02 *$ & $-12.32^{* *}$ & -0.63 & -3.96 & $166.97^{* *}$ & $146.41^{* *}$ \\
\hline PKVNL260 × A-95-B & -5.14 & $-12.41^{* *}$ & $-13.5^{* *}$ & $-22.30 * *$ & $59.45^{* *}$ & $43.78^{*}$ \\
\hline PKVNL260 xEC-1424 & 0.41 & -3.20 & -9.12 & $-22.12^{* *}$ & $139.79 * *$ & $124.88^{* *}$ \\
\hline PKVNL260 xGS-234 & 1.67 & -1.61 & -6.01 & -8.72 & $111.81^{* *}$ & $81.78^{* *}$ \\
\hline PKVNL260 xA-125 & -0.42 & -3.25 & 0.40 & -5.32 & $131.05^{* *}$ & $128.61^{* *}$ \\
\hline PKVNL260 xEita & -1.67 & -4.84 & $11.90^{*}$ & 9.70 & $260.36^{* *}$ & $200.75^{* *}$ \\
\hline PKVNL260 xGS-15 & $-9.60 *$ & -15.67 & 6.26 & 2.69 & $145.14^{* *}$ & $95.14^{* *}$ \\
\hline PKVNL260 xEC-1392 & 6.33 & 4.13 & -8.95 & $-16.18^{* *}$ & $91.84 * *$ & $57.96^{* *}$ \\
\hline PKVNL260 xPKDL-18 & -1.20 & -8.15 & 3.35 & $-12.50 * *$ & $214.44^{* *}$ & $184.33^{* *}$ \\
\hline PKVNL260 xAyogi & -2.52 & -4.92 & $-17.3^{* *}$ & $-18.87^{* *}$ & $70.54^{* *}$ & $64.18^{* *}$ \\
\hline PKVNL260 xES-44 & -2.81 & $-9.02 *$ & 9.00 & 1.34 & $127.44^{* *}$ & $99.25^{* *}$ \\
\hline PKVNL260 xEC-4168 & -1.65 & -5.56 & -7.66 & $-16.24 * *$ & $190.91^{* *}$ & $182.59 * *$ \\
\hline PKVNL260 xEC-9825 & 3.86 & 3.42 & -7.83 & $-13.26^{*}$ & $231.81^{* *}$ & $224.42^{* *}$ \\
\hline PKVNL260 xEC-544 & 0.86 & 0.86 & $11.83^{*}$ & 8.07 & $114.14 * *$ & $95.27^{* *}$ \\
\hline PKVNL260 xKL-178 & -2.38 & $-9.56^{*}$ & $11.49^{*}$ & 9.77 & $173.18^{* *}$ & $160.95^{* *}$ \\
\hline PKVNL260 x JRF-5 & -5.06 & $-13.48^{* *}$ & $-10.57^{*}$ & $-20.19 * *$ & $137.56^{* *}$ & $137.56^{* *}$ \\
\hline PKVNL260 xLCK-8605 & -2.90 & -6.40 & -4.40 & -7.81 & $54.36 * *$ & 16.46 \\
\hline PKVNL260 xBR-1 & -1.0 & -3.23 & $-16.5^{* *}$ & $-18.08^{* *}$ & $130.40 * *$ & $85.70^{* *}$ \\
\hline PKVNL260 x ACCNO447 & -4.31 & $-12.23^{* *}$ & 6.23 & 5.53 & $99.55^{* *}$ & $83.33^{* *}$ \\
\hline PKVNL260 x LCK88062 & -4.00 & $-10.45^{*}$ & 8.21 & 6.97 & 23.12 & 16.00 \\
\hline PKVNL260 xNeelum & -3.28 & -7.81 & 2.68 & 1.65 & $110.71 * *$ & $110.45^{* *}$ \\
\hline Padmini $\times$ A-95-B & -7.81 & $-13.87 * *$ & $-17.1^{* *}$ & $-27.66^{* *}$ & $112.27 * *$ & $78.15^{* *}$ \\
\hline Padmini xEC-1424 & -8.20 & $-10.40^{*}$ & 2.33 & -9.87 & $171.74^{* *}$ & $136.34^{* *}$ \\
\hline Padmini xGS-234 & -7.00 & -8.87 & 6.07 & -0.11 & $253.93^{* *}$ & $184.03^{* *}$ \\
\hline Padmini $\times A-125$ & -5.79 & -7.32 & -4.01 & $-12.14^{*}$ & $152.10^{* *}$ & $130.25^{* *}$ \\
\hline PadminixEita & 0.41 & -1.61 & -4.01 & -8.78 & $183.49^{* *}$ & $121.85^{* *}$ \\
\hline Padmini xGS-15 & $-10.67^{* *}$ & $-15.67^{* *}$ & -4.19 & -10.20 & $111.77^{* *}$ & $80.12^{* *}$ \\
\hline Padmini xEC-1392 & -1.67 & -2.48 & -3.79 & $-13.95^{*}$ & $105.43^{* *}$ & $58.82^{* *}$ \\
\hline Padmini xPKDL-18 & -7.09 & $-12.59 * *$ & $-11.16^{*}$ & $-26.71^{* *}$ & $103.43^{* *}$ & $71.17^{* *}$ \\
\hline PadminixAyogi & -0.41 & -1.64 & 5.88 & 4.49 & $167.45^{* *}$ & $138.24 * *$ \\
\hline Padmini xES-44 & -5.56 & $-10.53^{*}$ & 8.01 & -2.48 & $102.67 * *$ & $91.58^{* *}$ \\
\hline Padmini xEC-4168 & -2.04 & -4.76 & -5.77 & $-16.93^{* *}$ & $234.04 * *$ & $200.00 * *$ \\
\hline Padmini xEC-9825 & 4.24 & 3.36 & $-22.8^{* *}$ & $-29.48 * *$ & $99.61 * *$ & $88.03^{* *}$ \\
\hline Padmini xEC-544 & 4.68 & 3.36 & 4.55 & -2.02 & $127.96^{* *}$ & $93.28^{* *}$ \\
\hline Padmini xKL-178 & -0.39 & -6.62 & 7.17 & 2.27 & $109.03 * *$ & $84.87^{* *}$ \\
\hline Padmini xJRF-5 & -5.38 & $-12.7^{* *}$ & -7.72 & $-19.91 * *$ & $138.50 * *$ & $119.96^{* *}$ \\
\hline Padmini xLCK-8605 & -4.92 & -7.20 & $16.35^{* *}$ & 8.82 & $78.83 * *$ & $43.29 * *$ \\
\hline Padmini x BR-1 & -0.41 & -2.42 & 1.64 & 0.25 & $74.24 * *$ & $32.14 *$ \\
\hline Padmini xACCNO4/47 & $-10.08 *$ & $-16.5^{* *}$ & $-30.6^{* *}$ & $-32.40 * *$ & $-35.15^{* *}$ & $-35.42^{*}$ \\
\hline Padmini xLCK-88062 & 0.40 & -5.22 & 2.11 & 0.04 & $110.91^{* *}$ & $61.06^{* *}$ \\
\hline PadminixNeelum & -7.69 & $-10.94^{*}$ & $-12.83^{*}$ & $-16.37^{* *}$ & $40.02 * *$ & $28.99 *$ \\
\hline
\end{tabular}

MP: Mid-parent, BP: Better-parent.

* Significant at $5 \%$ and ${ }^{* *}$ Significant at $1 \%$

www.iosrjournals.org

15 | Page 
Estimation of Heterosis for Some Traits in Linseed (Linum Usitatissimum L.)

\begin{tabular}{|c|c|c|c|c|c|c|}
\hline Crosses & MP & $\mathrm{BP}$ & MP & $\mathrm{BP}$ & $\mathrm{MP}$ & $\mathrm{BP}$ \\
\hline 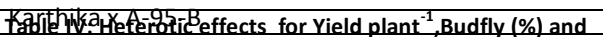 & $55.81^{*}$ & 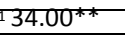 & \multicolumn{2}{|c|}{ Budfly $(\%) 0.90$} & \multicolumn{2}{|c|}{$33.64 * *$ Alternal4ad $\left(\sigma_{0}\right)^{* *}$} \\
\hline 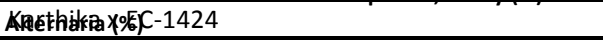 & $58.42^{* *}$ & $56.86^{* *}$ & -4.95 & -6.80 & $32.96 * *$ & $23.72^{* *}$ \\
\hline Karthika x GS-234 & $28.18^{* *}$ & 16.00 & -6.11 & -6.80 & $-22.46^{* *}$ & $-30.7^{* *}$ \\
\hline Karthika x A-125 & $41.18^{* *}$ & $20.00^{*}$ & -2.77 & -6.31 & $13.12^{*}$ & 5.85 \\
\hline Karthika x Eita & $61.67^{* *}$ & $45.50^{* *}$ & $-9.05 *$ & $-9.71 *$ & $17.42^{* *}$ & $12.35^{*}$ \\
\hline Karthika x GS-15 & -7.00 & $-20.9 * *$ & $-7.18^{*}$ & $-8.49 *$ & $35.35^{* *}$ & $33.24 * *$ \\
\hline Karthika x EC-1392 & $74.12^{* *}$ & $48.00^{* *}$ & -3.72 & -5.83 & $9.43^{*}$ & -10.79 \\
\hline Karthika x PKDL-18 & $28.09^{* *}$ & 14.00 & -6.19 & $-7.94^{*}$ & $9.81^{*}$ & 0.08 \\
\hline KarthikaxAyogi & -5.05 & -6.00 & -6.34 & -6.80 & $34.53^{* *}$ & $13.15^{* *}$ \\
\hline Karthika x ES-44 & 10.46 & -5.04 & $-7.14^{*}$ & $-8.88^{*}$ & 2.22 & 0.27 \\
\hline Karthika x EC-4168 & $68.82^{* *}$ & $57.00 * *$ & -2.69 & -3.40 & $36.26 * *$ & $23.25^{* *}$ \\
\hline Karthika x EC-9825 & $89.53^{* *}$ & $63.00^{* *}$ & -1.73 & -3.40 & $40.43^{* *}$ & $31.36^{* *}$ \\
\hline Karthika x EC-544 & $50.03^{* *}$ & $36.00 * *$ & 3.02 & -0.49 & $18.30^{* *}$ & $11.34^{*}$ \\
\hline Karthika x KL-178 & $36.02^{* *}$ & $35.00 * *$ & $-10.0^{* *}$ & $-11.68^{* *}$ & $13.51^{*}$ & 9.06 \\
\hline Karthika x JRF-5 & $-15.3^{*}$ & $-27.66^{* *}$ & -5.75 & $-10.48 * *$ & $19.31^{* * *}$ & 8.32 \\
\hline Karthika x LCK-8605 & 0.00 & -8.33 & -6.15 & $-11.59 * *$ & 4.54 & -0.26 \\
\hline Karthika x BR-1 & $94.67^{* *}$ & $46.00^{* *}$ & $-7.96^{*}$ & $-10.19 *$ & $17.38^{* *}$ & 3.46 \\
\hline Karthika x ACCNO4/47 & $41.44^{* *}$ & $28.00^{* *}$ & -5.94 & $-7.91^{*}$ & $17.56^{* *}$ & 9.05 \\
\hline Karthika x LCK-88062 & $68.27^{* *}$ & $62.04 * *$ & -4.56 & -5.69 & 1.09 & $-16.0 * *$ \\
\hline KarthikaxNeelum & $26.36^{* *}$ & $15.83^{*}$ & -2.40 & -3.33 & $20.69 * *$ & 6.14 \\
\hline PKVNL260 × A-95-B & $111.8^{* *}$ & $100.00^{* *}$ & -3.86 & $-10.36^{* *}$ & $37.70^{* *}$ & $19.92^{* *}$ \\
\hline PKVNL260 xEC-1424 & $30.12^{* *}$ & 5.88 & 0.51 & -1.01 & $45.20^{* *}$ & $26.15^{* *}$ \\
\hline PKVNL260 xGS-234 & $57.93^{* *}$ & $41.36^{* *}$ & -0.76 & -3.45 & $16.78^{* *}$ & $11.96^{*}$ \\
\hline PKVNL260 xA-125 & $85.07^{* *}$ & $77.14^{* *}$ & 1.31 & 1.04 & $29.77^{* *}$ & $28.66^{* *}$ \\
\hline PKVNL260 xEita & $100.00 * *$ & $80.00 * *$ & -1.77 & -4.43 & 5.56 & 2.27 \\
\hline PKVNL260 xGS-15 & 10.14 & $-20.28 * *$ & -6.93 & $-11.32 * *$ & $31.50^{* *}$ & $23.89 * *$ \\
\hline PKVNL260 xEC-1392 & $92.54 * *$ & $84.29 * *$ & 5.40 & 4.06 & $-12.12 * *$ & $-23.7^{* *}$ \\
\hline PKVNL260 xPKDL-18 & $101.41^{* *}$ & $83.33^{* *}$ & -6.40 & $-11.21 * *$ & 7.26 & 5.13 \\
\hline PKVNL260 xAyogi & $22.22^{* *}$ & 1.02 & -0.51 & -3.43 & $-12.20 * *$ & $-21.1^{* *}$ \\
\hline PKVNL260 xES-44 & $24.14^{*}$ & -9.35 & -4.93 & $-9.81 *$ & 9.29 & 3.32 \\
\hline PKVNL260 xEC-4168 & $113.33^{* *}$ & $86.05^{* *}$ & -3.80 & -6.40 & $31.13^{* *}$ & 11.01* \\
\hline PKVNL260 xEC-9825 & $117.65^{* *}$ & $105.56^{* *}$ & -2.81 & -4.52 & $18.78^{* *}$ & $17.81^{* *}$ \\
\hline PKVNL260 xEC-544 & $34.89 * *$ & 20.54 & -1.04 & -1.04 & 1.15 & -0.32 \\
\hline PKVNL260 xKL-178 & $42.77^{* *}$ & $17.77^{* *}$ & -3.45 & $-8.41 *$ & $14.73^{* *}$ & $10.69 * *$ \\
\hline PKVNL260 x JRF-5 & $13.17^{*}$ & -17.73 & $-8.31 *$ & $-15.72 * *$ & $23.36^{* *}$ & 4.78 \\
\hline PKVNL260 xLCK-8605 & $19.57^{*}$ & -8.33 & $-10.6^{* *}$ & $-18.45^{* *}$ & $14.00^{* *}$ & $10.77^{* *}$ \\
\hline PKVNL260 xBR-1 & $64.91^{* *}$ & $46.87^{* *}$ & -2.06 & -3.06 & $23.04^{* *}$ & $16.29 * *$ \\
\hline PKVNL260 x ACCNO447 & $48.28^{* *}$ & $32.72^{* *}$ & -2.70 & $-7.91 *$ & $14.00^{* *}$ & $13.90^{* *}$ \\
\hline PKVNL260 x LCK88062 & $74.42^{* *}$ & $38.89^{* *}$ & $-10.1^{* *}$ & $-14.22 * *$ & $21.79^{* *}$ & 7.87 \\
\hline PKVNL260 xNeelum & $39.13^{* *}$ & 6.67 & 0.50 & -3.81 & $20.80^{* *}$ & -0.32 \\
\hline Padmini $\times$ A-95-B & $84.42^{* *}$ & $73.17^{* *}$ & -4.47 & $-8.56^{*}$ & $19.36^{* *}$ & 0.90 \\
\hline Padmini xEC-1424 & $67.39 * *$ & $50.98 * *$ & $-9.23 *$ & $-10.34^{*}$ & $17.39^{* *}$ & -0.98 \\
\hline Padmini xGS-234 & $139.26 * *$ & $137.80^{* *}$ & -2.96 & -2.96 & 4.42 & 3.64 \\
\hline Padmini xA-125 & $92.11^{* *}$ & $78.05^{* *}$ & 2.54 & -0.49 & -3.86 & -7.92 \\
\hline PadminixEita & $92.59^{* *}$ & $90.24^{* *}$ & -6.90 & -6.90 & 5.96 & -0.75 \\
\hline Padmini xGS-15 & $58.22^{* *}$ & $24.48^{* *}$ & $-8.43 *$ & $-10.38^{*}$ & $25.31^{* *}$ & $14.25^{* *}$ \\
\hline Padmini xEC-1392 & $55.26^{* *}$ & $43.90^{* *}$ & $-9.50 *$ & $-10.84^{*}$ & $-8.46 *$ & $-18.0^{* *}$ \\
\hline Padmini xPKDL-18 & $73.13^{* *}$ & $68.90^{* *}$ & $-7.91^{*}$ & $-10.28^{*}$ & $-17.08^{* *}$ & $-18.3^{* *}$ \\
\hline PadminixAyogi & $66.67^{* *}$ & $53.06 * *$ & -4.18 & -4.41 & $14.49 * *$ & 6.19 \\
\hline Padmini xES-44 & $59.28^{* *}$ & $26.62^{* *}$ & -6.00 & $-8.41^{*}$ & 4.12 & -4.75 \\
\hline Padmini xEC-4168 & $114.29 * *$ & $109.30 * *$ & $-7.39 *$ & -7.39 & $20.35^{* *}$ & -0.98 \\
\hline Padmini xEC-9825 & $131.17^{* *}$ & $117.07^{* *}$ & $-7.96 *$ & $-8.87 *$ & $14.36^{* *}$ & 9.58 \\
\hline Padmini xEC-544 & $73.91^{* *}$ & $73.17^{* *}$ & -2.28 & -4.93 & $13.90^{* *}$ & 8.45 \\
\hline Padmini XKL-178 & $80.61^{* *}$ & $65.48^{* *}$ & $-7.43^{*}$ & $-9.81 *$ & $-16.73 * *$ & $-22.3^{* *}$ \\
\hline Padmini xJRF-5 & $24.66^{* *}$ & -1.42 & $-11.1^{* *}$ & $-16.16^{* *}$ & $16.77^{* *}$ & -3.62 \\
\hline Padmini xLCK-8605 & 8.91 & -8.33 & $-15.6^{* *}$ & $-21.03 * *$ & 8.87 & 2.26 \\
\hline Padmini x BR-1 & $54.55^{* *}$ & $24.39 *$ & -4.26 & -5.91 & $16.18^{* *}$ & $13.63^{* *}$ \\
\hline Padmini xACCNO4/47 & $28.83^{* *}$ & $28.05^{*}$ & -5.26 & $-7.91 *$ & 2.07 & -1.36 \\
\hline Padmini xLCK-88062 & $91.16^{* *}$ & $68.15^{* *}$ & -0.48 & -2.37 & -4.95 & $-13.1^{* *}$ \\
\hline PadminixNeelum & 2.97 & -13.33 & $-10.9 * *$ & $-12.38^{* *}$ & $-22.22^{* *}$ & $-37.6^{* *}$ \\
\hline
\end{tabular}

Table III: Heterotic effects for Branches plant ${ }^{-1}$, Days to maturity and 1000 seed weight

MP: Mid-parent, BP: Better-parent. $\quad *$ Significant at $5 \%$ and $* *$ Significant at $1 \%$ 
Estimation of Heterosis for Some Traits in Linseed (Linum Usitatissimum L.)

\begin{tabular}{|c|c|c|c|c|c|c|}
\hline Crosses & MP & $\mathrm{BP}$ & MP & $\mathrm{BP}$ & MP & $\mathrm{BP}$ \\
\hline Karthika x A-95-B & 49.23 & 38.68 & $48.77^{* *}$ & $26.64^{*}$ & -24.37 & $-38.58^{* *}$ \\
\hline Karthika x EC-1424 & $83.71^{* *}$ & 53.30 & -18.24 & -19.28 & -10.63 & -24.48 \\
\hline Karthika x GS-234 & 47.42 & 22.43 & $35.71^{* *}$ & 9.28 & -17.28 & $-42.18^{* *}$ \\
\hline Karthika x A-125 & $60.35^{*}$ & 52.49 & -0.90 & $-27.56^{*}$ & 7.03 & $-21.75^{*}$ \\
\hline Karthika x Eita & $198.75^{* *}$ & $178.44^{* *}$ & 10.62 & -9.68 & -7.21 & $-33.32 * *$ \\
\hline Karthika x GS-15 & 31.12 & 9.89 & 1.37 & -3.78 & $25.90^{*}$ & -9.29 \\
\hline Karthika x EC-1392 & $150.99 * *$ & $105.04^{* *}$ & -0.68 & -18.22 & 22.43 & 12.22 \\
\hline Karthika x PKDL-18 & $117.51^{* *}$ & $87.70^{* *}$ & 2.37 & -1.88 & 10.83 & -16.96 \\
\hline Karthika x Ayogi & $50.86^{*}$ & 43.52 & $-32.08^{* *}$ & $-43.69^{* *}$ & $35.61^{*}$ & 17.80 \\
\hline Karthika x ES-44 & $66.39 *$ & $63.87^{*}$ & -10.91 & $-27.16^{* *}$ & -5.89 & $-34.76 * *$ \\
\hline Karthika x EC-4168 & $170.18^{* *}$ & $151.08^{* *}$ & $51.85^{* *}$ & 7.24 & $38.56^{*}$ & 15.38 \\
\hline Karthika x EC-9825 & 44.07 & 42.47 & 17.31 & -16.63 & -18.04 & -18.73 \\
\hline Karthika x EC-544 & $109.76^{* *}$ & $87.97^{* *}$ & 26.40 & -17.77 & -11.06 & $-31.67^{*}$ \\
\hline Karthika x KL-178 & $92.07^{* *}$ & $65.22^{*}$ & $28.33^{* *}$ & $23.84^{*}$ & 23.75 & 23.70 \\
\hline Karthika x JRF-5 & $153.57^{* *}$ & $109.37^{* *}$ & $-26.13^{*}$ & $-46.81 * *$ & -14.29 & -29.50 \\
\hline Karthika x LCK-8605 & $123.98^{* *}$ & $77.62^{* *}$ & -10.30 & $-26.49 *$ & $59.31 * *$ & $34.65^{*}$ \\
\hline Karthika x BR-1 & $119.27^{* *}$ & $88.03^{* *}$ & 7.86 & -16.90 & $42.49 * *$ & 3.33 \\
\hline Karthika x ACCNO4/47 & $161.55^{* *}$ & $148.54^{* *}$ & $-33.07 * *$ & $-35.72^{* *}$ & 3.87 & $-25.91^{*}$ \\
\hline Karthika x LCK-88062 & $85.69^{*}$ & 50.05 & 15.90 & 13.73 & $29.30 *$ & -2.35 \\
\hline Karthika x Neelum & 53.59 & 22.97 & $70.20 * *$ & $49.06 * *$ & $74.20 * *$ & $55.08^{*}$ \\
\hline PKVNL260 x A-95-B & -16.82 & -28.31 & $45.73 * *$ & 17.54 & -10.25 & -18.93 \\
\hline PKVNL260 x EC-1424 & 69.64* & 32.65 & $50.03 * *$ & 8.16 & -3.53 & -16.57 \\
\hline PKVNL260 x GS-234 & 25.22 & -2.51 & 29.86 & 10.74 & -14.28 & $-23.26^{*}$ \\
\hline PKVNL260 x A-125 & $176.01 * *$ & $142.92^{* *}$ & 28.54 & 24.22 & $-24.33^{*}$ & $-27.43^{*}$ \\
\hline PKVNL260 x Eita & $211.76^{* *}$ & $169.41^{* *}$ & 22.30 & 2.76 & $-37.45^{* *}$ & $-41.57 * *$ \\
\hline PKVNL260 x GS-15 & $87.20^{* *}$ & $68.68 * *$ & -24.54 & $-44.18 * *$ & $-24.30 *$ & $-29.00 * *$ \\
\hline PKVNL260 x EC-1392 & 18.75 & -8.90 & 12.33 & -6.44 & -4.46 & $-32.19 * *$ \\
\hline PKVNL260 x PKDL-18 & $132.29 * *$ & $87.21^{* *}$ & $-46.03^{* *}$ & $-60.34^{* *}$ & $-37.80 * *$ & $-38.11^{* *}$ \\
\hline PKVNL260 x Ayogi & 44.04 & 39.27 & 31.90 & 9.12 & -9.13 & $-23.54^{*}$ \\
\hline PKVNL260 x ES-44 & $93.77^{* *}$ & $76.07^{* *}$ & $-46.47 * *$ & $-65.91 * *$ & $-24.68 * *$ & $-33.43^{* *}$ \\
\hline PKVNL260 x EC-4168 & $54.97 *$ & 33.56 & $61.93^{* *}$ & $58.50 *$ & $-29.50 *$ & $-38.08 * *$ \\
\hline PKVNL260 x EC-9825 & $157.07^{* *}$ & $134.47^{* *}$ & 31.51 & 30.08 & $-49.94 * *$ & $-62.58^{* *}$ \\
\hline PKVNL260 x EC-544 & $73.36^{* *}$ & 44.57 & $53.83^{*}$ & 30.69 & 2.53 & -0.63 \\
\hline PKVNL260 x KL-178 & $154.26 * *$ & $104.34 * *$ & $-36.38^{*}$ & $-53.45^{* *}$ & -3.36 & $-27.37^{*}$ \\
\hline PKVNL260 x JRF-5 & $121.08^{* *}$ & $71.23^{* *}$ & 14.73 & 13.52 & -18.08 & $-27.07^{*}$ \\
\hline PKVNL260 x LCK-8605 & $51.99 * *$ & 28.83 & -25.84 & $-37.93^{*}$ & -2.66 & -15.84 \\
\hline PKVNL260 x BR-1 & 52.11 & 21.89 & $74.10^{* *}$ & $56.35^{* *}$ & $-41.96 * *$ & $-45.03 * *$ \\
\hline PKVNL260 x ACCNO447 & $58.49^{*}$ & $53.42^{*}$ & -9.05 & $-36.49 * *$ & $-47.19 * *$ & $-51.22^{* *}$ \\
\hline PKVNL260 x LCK88062 & -5.03 & -27.85 & $48.16^{* *}$ & 4.80 & -7.29 & -7.92 \\
\hline PKVNL260 x Neelum & 32.94 & 0.16 & $73.30 * *$ & $36.31^{*}$ & $-33.42 *$ & $-53.63 * *$ \\
\hline Padmini x A-95-B & 44.10 & 29.87 & $43.45^{*}$ & 10.46 & -8.99 & -9.13 \\
\hline Padmini x EC-1424 & $157.32^{* *}$ & $109.11^{* *}$ & -25.82 & $-48.47^{* *}$ & $-50.58 * *$ & $-52.86^{* *}$ \\
\hline Padmini x GS-234 & $174.18^{* *}$ & $121.77^{* *}$ & 30.29 & 5.63 & -15.45 & $-30.86^{* *}$ \\
\hline Padmini $\times$ A-125 & $174.45^{* *}$ & $152.91 * *$ & 13.19 & 3.09 & -13.39 & $-24.72 *$ \\
\hline Padmini x Eita & $111.76^{* *}$ & $91.39 * *$ & -17.52 & $-34.04^{*}$ & $-20.56^{* *}$ & $-32.56 * *$ \\
\hline Padmini x GS-15 & $132.73^{* *}$ & $100.55^{* *}$ & -25.34 & $-46.90 * *$ & -18.95 & $-30.94^{* *}$ \\
\hline Padmini x EC-1392 & $118.12^{* *}$ & $73.67^{*}$ & -24.20 & $-39.87^{*}$ & $48.40^{* *}$ & 12.92 \\
\hline Padmini x PKDL-18 & $113.27 * *$ & $78.99 * *$ & $-37.87^{*}$ & $-56.08 * *$ & $-25.28^{*}$ & $-32.90 * *$ \\
\hline Padmini $x$ Ayogi & $155.01^{* *}$ & $150.65^{* *}$ & $-50.83^{* *}$ & $-61.24^{* *}$ & -15.23 & -21.62 \\
\hline Padmini x ES-44 & $137.98^{* *}$ & $126.84 * *$ & $-49.25^{* *}$ & $-68.51 * *$ & $-29.43 * *$ & $-42.93^{* *}$ \\
\hline Padmini x EC-4168 & $162.92^{* *}$ & $136.96^{* *}$ & -34.76 & -37.37 & $-50.25 * *$ & $-51.72^{* *}$ \\
\hline Padmini x EC-9825 & $56.14^{*}$ & 49.42 & 17.91 & 12.05 & -17.49 & $-33.35^{*}$ \\
\hline Padmini x EC-544 & $128.36^{* *}$ & $98.73^{* *}$ & -9.67 & -18.99 & -8.90 & -15.42 \\
\hline Padmini x KL-178 & $110.59 * *$ & $76.20 * *$ & -1.55 & $-30.69^{*}$ & 22.40 & -0.50 \\
\hline Padmini x JRF-5 & $217.86 * *$ & $155.70^{* *}$ & $61.44 * *$ & $50.33^{*}$ & $-47.98 * *$ & $-48.74 * *$ \\
\hline Padmini x LCK-8605 & $135.51 * *$ & $91.59 * *$ & $45.94 *$ & 16.30 & $70.69 * *$ & $62.76 * *$ \\
\hline Padmini x BR-1 & $69.95^{*}$ & 41.77 & $54.27^{* *}$ & 31.23 & $-39.15^{* *}$ & $-47.69 * *$ \\
\hline Padmini x ACCNO4/47 & -16.27 & -17.80 & 11.93 & $-24.48^{*}$ & $77.20^{* *}$ & $48.97 * *$ \\
\hline Padmini x LCK-88062 & 67.07* & 31.65 & $37.45^{* *}$ & -6.17 & -7.51 & -16.06 \\
\hline Padmini $\times$ Neelum & 39.71 & 9.11 & $-41.32 *$ & $-55.85^{* *}$ & 0.98 & -24.83 \\
\hline
\end{tabular}

MP: Mid-parent, BP: Better-parent.

* Significant at $5 \%$ and ${ }^{* *}$ Significant at $1 \%$ 